\title{
The Phenomenal Presence of Perceptual Reasons
}

\author{
Fabian Dorsch
}

Forthcoming in: Phenomenal Presence, edited by F. Macpherson \& F. Dorsch, Oxford: Oxford University Press.

\section{Doxasticism vs. Experientialism about Our Ac- cess to Reasons}

It is very common to endorse doxasticism about our awareness of normative (or justifying) reasons, according to which we can recognise our reasons for forming attitudes or performing actions only by means of normative judgements or beliefs. In other words, it is often assumed that we can identify things (e.g. facts, considerations, mental states or episodes, etc.) that do constitute reasons for us and discriminate them from things that do not only by means of judging or believing that things of the first kind (but not of the second) are reasons for us. ${ }^{\mathrm{I}}$

Take the case of two people who both see that a third person is injured and in distress. While one of the two recognises that she has a reason to help the hurt (and subsequently helps him), the other fails to do so (e.g. because of a lack of moral sensitivity). What doxasticism maintains is that the basic difference between the two is that only the first has formed the judgement or belief that she has a reason to help the third person (and is acting accordingly).

Similarly, of two people, who have read the same newspaper article about the political situation in a rather unknown country, only one of them may take the article to provide them with a reason to believe that the government of the country in question needs to resign or be removed (e.g. because one of the two does not trust the newspaper concerned). Again, according to doxasticism, the two people differ primarily in

${ }^{\text {I }}$ Among the many philosophers who endorse doxasticism are Kant, (I785/1999), Sellars, (I956/1997), Davidson, (I982), McDowell, (I998), Dancy, (2000, e.g. p. I26) and Setiya, (20II, e.g. p. I3I). Indeed, their endorsement is typically implicit - rather than explicit - in that they normally do not even consider the possibility that doxasticism might be false. Note also that doxasticists need not claim - although many of them do claim - that motivation or justification require the recognition of reasons. For instance, it is compatible with doxasticism that someone acts for a reason without having any relevant normative belief. 
their normative judgements or beliefs (as well as in their subsequent belief about the country).

One of the main problems with doxasticism is that it renders the following triad of claims jointly inconsistent (the same point may perhaps also be made with respect to certain higher animals):

(I) Being motivated (i.e. forming attitudes or performing actions for a motive) requires responding to and, hence, recognising a relevant reason.

(2) Infants are capable of being motivated.

(3) Infants are incapable of normative judgement or belief.

It should be clear that $(3)$ is true. Infants cannot form normative judgements or beliefs of the form 'this gives me a reason to believe $p$, or to do $A$ ', given that they neither possess normative concepts (like 'reason'), nor are they capable of reflective thought, partly because they lack a proper first-personal conception of themselves. So doxasticists have to reject either (I) or (2) (or both). But this forced choice may be understood as a dilemma for doxasticism.

On the hand, doxasticists may adopt a Kantian approach and reject the idea that infants are capable of forming attitudes or performing actions in a motivated way precisely because motivation presupposes the doxastic recognition of reasons, and because infants lack the capacity to doxastically recognise reasons. ${ }^{2}$ But this choice seems to wrongly reduce the responses of infants to reflexes or instinctive reactions (i.e. to animal-like behaviour). When infants reach for some object that caught their attention or start to cry when their parents leave the room, their behaviour can be made perfect sense of in terms of motives (e.g. that they want to take a closer look at the object, or to be near to their parents). Moreover, it does not seem to differ substantially (other than in aspects of execution and control) from the comparable behaviour of adults who pick up an object because they want to investigate it further, or call after their beloved one because they do not want them to leave.

On the other hand, doxasticists may choose a Humean route and deny that motivation is a matter of (recognising and responding to) reasons. Instead, they espouse a purely causal or teleological account of motivation. ${ }^{3}$ In this way, they can accommodate the observation that the responses of infants are motivated, despite the fact that infants do not possess the conceptual and reflective capacities required for normative judgement or belief. But they pay the price of detrimentally ignoring the rational nature of (some instances of) motivation. That our formation of attitudes and performance of actions are (at least sometimes) intelligible from the rational perspective

\footnotetext{
${ }^{2}$ See, for instance, Davidson, (1982), as well as Kant, (1785/1999) and McDowell, (1998, pp. 29f. and Io8ff.) on the comparable case of higher animals..

${ }^{3}$ See, for instance, Hume, (1739/2007, \$ 2.3.3), Mele, (2003, Ch. 2) and Smith, (1994, Introduction). Note that, although Smith and other Humeans talk of 'motivating' or 'explaining reasons', they strictly distinguish these from normative (i.e. justifying) reasons. When I speak of 'reasons', I have always normative reasons in mind.
} 
is evidenced by the fact that we can - and do - justify them by reference to relevant facts, considerations, mental states or episodes, and so on. When asked why we have picked up an object or called someone back, we do not merely provide a causal explanation, but point to reasons for performing these actions - that is, for things that we take to speak in favour of the actions (e.g. that we need to find out how the object works, or that we have the strong desire not to be separated from our beloved one).

The doxasticists are therefore trapped between the two options of over and of underintellectualising motivation. The Kantians demand too much of motivation by requiring the involvement of normative judgement or belief - with the adverse result that they erroneously fail to count infants as being capable of motivated responses. The Humeans, on the other hand, demand too little of motivation by not requiring any recognition of, or responses to, reasons - meaning that they wrongly deny that the attitudes and actions of us (i.e. both adults and infants) could be rational.

One elegant way of avoiding this dilemma is to give up doxasticism and instead endorse experientialism - the view that we enjoy some experiential access to reasons, which is independent of, and perhaps more fundamental than, our capacity to form normative judgements and beliefs. ${ }^{4}$ In this paper, I would like to provide an argument for the existence of such a non-doxastic form of access to reasons. More specifically, I aim to defend the view - which I have called elsewhere experiential rationalism (Dorsch, 2OII, Introduction) - that our basic awareness of reasons for us is phenomenal in nature. What this means is that it forms part of our access from the inside to those of our mental episodes, that provide us with reasons either by constituting the reasons themselves, or alternatively by bringing us into contact with reason-constituting facts or considerations. In other words, when we introspectively attend to those reason-giving mental episodes and what they are about, we have the impression of the presence of a reason for us.

Experientialists need not assume that reasons are phenomenally present to us. They could instead maintain that our access to reasons is perceptual or emotional. However, it is not only difficult to identify actual endorsements of this alternative to experiential rationalism view. But taking our experiential access to reasons to be sensory or affective also does not enjoy much plausibility. Most important, reasonconstituting things do not differ from other things in being linked to a distinctive visual look or emotional feeling, which would allow us to discriminate the two kinds of thing from each other. In addition, at least emotional responses are themselves subject to rational assessment, thus posing the threat of a malicious form of regress. For if our emotional recognition of our reason to perform a certain action is itself in need of rational support, it has to be based on a further emotional feeling making us aware of our reason to have our first affective response; and so on. ${ }^{5}$

\footnotetext{
${ }_{4}$ Note that doxasticism and experientialism need not disagree about the non-inferentiality of our basic recognition of reasons. For doxasticists may insist that the relevant normative judgements or beliefs are intuitive in nature, rather than being the result of reasoning.

5 The same problem might actually arise for normative judgements or beliefs, too. But doxasticists
} 
My defence of experiential rationalism - as an alternative to both doxasticism and the perceptual or emotional versions of experientialism - focuses exclusively on perceptual reasons for first-order beliefs about the external world. I aim to argue for our phenomenal access to other kinds of reason - including practical ones - elsewhere. ${ }^{6}$ Including this introductory section, the chapter consists of five parts.

In the second one, I argue that the best interpretation of the dispute between intentionalists and sense-data theories about the significance of hallucinations for theories of perception involves the claim that, from the inside, our perceptual experiences seem (rightly or wrongly) to be genuine relations to external objects. The following section describes this impression of relationality in more detail and concludes that it involves an impression of determination by the objects of perception and their perceived features. The fourth section defends the claim that this impression of deter mination constitutes one particular (i.e. the perceptual) way of being experientially aware of reasons for belief. In seeming to be determined by external objects and their features, perceptual experiences appear from the inside to provide us with a reason to ascribe in belief those features to those objects. In the fifth and final section, I point out that the resulting impression of perceptual reason-provision is neither sensory (or experiential), nor intellectual (or cognitive), thus embodying a second kind of introspectively accessible, non-sensory aspects of mental episodes, in addition to what is sometimes called 'cognitive phenomenology' (Bayne and Montague, 20II).7 I argue that aspects of this second non-sensory kind are best understood as structural aspects of mental episodes (i.e. aspects that do not vary among the distinct instances of a given kind of mental episode); and that the debate about the existence of nonsensory aspects of mental episodes should focus on these aspects, rather than (just) on intellectual aspects.

\section{The Argument from Hallucination}

The crucial element in our impression of perceptual reason-provision is the seeming relationality of perceptual experiences. That perceptual experience do appear to be relational from the inside becomes apparent in the debate about hallucinations and, in particular, about the significance of the sense-data version and the intentionalist version of the argument from hallucination. It is therefore necessary to take a closer look at this debate.

have still the option to argue that normative judgements are self-justifying - for instance, because they involve rational intuition (Bealer, 2002), or because they concern conceptual normative truths. Neither option is open to experientialists that take our access to reasons to be emotional, given that emotional feelings cannot justify themselves.

6 To some extent, I already started to work on this project in Dorsch, (2009b) with respect to reasons for judging and for acting, and in Dorsch, (2013) with respect to perceptual reasons.

7 Strictly speaking, 'cognitive phenomenology' is a misnomer, given that, traditionally, phenomenology is a method of describing and investigating mental episodes and other things from the inside, and not a synonym for 'phenomenal character' (i.e. what mental episodes are like for us from the inside). 
Naive realism about perceptual experiences claims that these experiences relate us to external objects and features - that is, to objects that exist, and to features that are instantiated by those objects, independently of being experienced by us. ${ }^{8}$ The view is naive in so far as it intends to take appearances at face value. That is, it maintains that perceptual experiences are exactly like they seem to be from the inside (or in introspection). ${ }^{9}$ Accordingly, naive realists assume that perceptual experience are given to us from the inside as relations to external entities. That this assumption is at the core of naive realism becomes apparent if we consider two traditional ways of arguing against naive realism, both of which make essential use of the possibility of perfect (or perception-like) hallucinations.

Perfect hallucinations are experiences that are, from the inside, indistinguishable from veridical perceptions, but do not relate us to any external objects or features. They are problematic for naive realism since they constitute a counterexample to the claim that all perceptual experiences are relations to external objects, at least on the assumption that perfect hallucinations are perceptual experiences. Because of this challenge, it has been common to reject naive realism by denying either that perceptual experiences are relational, or that they relate us external entities. ${ }^{\mathrm{IO}}$ Sense-data theory, for example, may be supported by the following sense-data argument from hallucination: ${ }^{\text {II }}$

(i) Perceptual experiences are essentially relationally linked to their objects of awareness.

(ii) There can be perfect hallucinations, which are experiences that are not rela-

${ }^{8}$ According to a stronger understanding, it claims that perceptual experiences make us relationally areare of external entities (Martin, 2002b; Nudds, 2009). In Dorsch and Soldati, (2016), Gianfranco Soldati and me argue that naive realism is compatible with treating perceptual experiences as involving intentional awareness.

9 In what follows, I use 'access from the inside' and 'introspection' interchangeably. I thus assume that introspection need not be limited to our capacity for introspective judgements, but may also include a phenomenal (or experiential) form of awareness of, or attention to, our own mental episodes. In Dorsch, (2013), I have argued - contrary to Martin, (2006, 4Iff.) - that this phenomenal awareness from the inside is distinct from, and prior to, our capacity for introspective judgements in the sense that it can occur without introspective judgement, but not vice versa, given that introspective judgements are based on instances of phenomenal awareness (compare, for instance, Peacocke, (2009) on our awareness of our own actions). Being phenomenally aware of a mental episode simply means having or enjoying a conscious mental episode - for instance, experiencing, thinking or feeling something - and requires neither the possession of the 'I'-concept, nor the possession of mental concepts, such as 'thinking' or 'judging' (Dorsch, 20I3; Dorsch and Soldati, 20I6).

${ }^{10}$ One could also deny both in the light of the possibility of hallucinations and thus endorse the view that perceptual experiences make us intentionally aware of sense data. But this is both unnecessary and implausible (especially if sense-data are conceived of as experience-dependent), explaining why this position has, as far as I know, never been defended.

II The argument is sometimes presented in terms of fundamental mental kinds of experience rather than in terms of essences (Martin, 2004b). But I do not think that it matters for what follows whether the crucial issue is whether veridical perceptions and hallucinations are of the same fundamental mental kind, or rather whether they share the same nature. 
tionally linked to external objects of awareness.

(iii) Perfect hallucinations are essentially perceptual experiences.

(iv) Hence, perceptual experiences are essentially linked to non-external objects of awareness.

Although it is not easy to find explicit statements of arguments like this in the writings of sense-data theorists (whether they are indirect realists or idealists), it is clear that many of them endorse all three premisses. Premiss (ii) is just the observation that perfect hallucinations are possible; while premiss (iii) expresses the view that veridical perceptions and perfect hallucinations are experiences of the same fundamental kind, that is, with the very same nature. Both premisses have been relatively uncontroversial until the (re)emergence of relationalist theories of perception that are paired with direct realism (*). Premiss (iii), on the other hand, has been identified most closely with sense-data theory and has been the primary target of its opponents. The following exemplary quotations bear witness to the fact that premiss (i) is indeed explicit in sense-data theory, given that the claim about the relationality of perceptual experiences is nothing but the claim that the second relatum - the object of awareness always exists:

When I say 'This table appears brown to me' it is quite plain that I am acquainted with an actual instance of brownness (or equally plainly with a pair of instances when I see double). This cannot indeed be proved, but it is absolutely evident and indubitable. (Price, I98I, p. 63)

When I see a tomato there is much that I can doubt. I can doubt whether there is a tomato that I am seeing, and not a cleverly painted piece of wax. I can doubt whether there is any material thing there at all. Perhaps what I took for a tomato was really a reflection; perhaps I am even the victim of some hallucination. One thing however I cannot doubt: that there exists a red patch of a round and somewhat bulgy shape, standing out from a background of other colourpatches, and having a certain visual depth, and that this whole field of colour is directly present to my consciousness. What the red patch is, whether it is physical or psychical or neither, are questions that we may doubt about. But that something is red and round then and there I cannot doubt. (Price, I98I, p. 3)

(Phenomenal Principle) If there sensibly appears to a subject to be something which possesses a particular sensible quality then there is something of which the subject is aware which does possess that sensible quality. (Robinson, 1994, p. 32)

However, the modus ponens of the sense-data theorists is the modus tollens of the intentionalists. For, according to the intentionalist argument from ballucination, we should reject premiss (i) precisely on the basis of the other two premisses and the negation of the conclusion (iv):

(iv*) Perceptual experiences are essentially linked to external objects of awareness. 
(ii) There can be perfect hallucinations, which are experiences that are not relationally linked to external objects of awareness.

(iii) Perfect hallucinations are essentially (* the same as veridical) perceptual experiences.

(i*) Hence, perceptual experiences are essentially non-relationally linked to their objects of awareness.

Intentionalists support their central premiss $\left(\mathrm{iv}^{*}\right)$ by reference to the so-called transparency of experience. The idea that perceptual (and other kinds of) experience are transparent can be understood in different ways. The strongest reading can be found expressed in passages like the following:

'[B]lue' is as much an object, and as little a mere content, of my experience, when I experience it, as the most exalted and independent real thing of which I am ever aware. [...] [It] is as truly and really not a part of my experience, as anything which I can ever know. (Moore, I903, 450f.)

Focus your attention on a square that has been painted blue. Intuitively, you are directly aware of blueness and squareness as out there in the world away from you, as features of an external surface. Now shift your gaze inward and try to become aware of your experience itself, inside you, apart from its objects. Try to focus your attention on some intrinsic feature of the experience that distinguishes it from other experiences, something other than what it is an experience of. The task seems impossible: one's awareness seems always to slip through the experience to blueness and squareness, as instantiated together in an external object. (Tye, I995, 30f.)

According to the stronger reading, perceptual experiences are transparent in the sense that attention to them from the inside reveals nothing but external objects of awareness and their features. In particular, it discloses neither non-external objects of awareness (e.g. sense-data or inner pictures that depend for their existence on being experienced by us), nor features of the perceptual experiences themselves other than their property of being experiences of certain external objects with certain features. Weaker readings agree that the only objects of perception open to introspective attention seem to be external. But they leave it open whether we have access from the inside to other features of perceptual experiences:

There is a positive and a negative side to the claim here: that one does encounter the mind-independent world in experience; and that one encounters nothing else. We might call the positive thesis Transparency: that the character of one's experience involves in some sense, or is directed on or of the mind-independent objects and their features which we take to be around us in our environment. (Martin, 2004b, ch.I, p. 3I)

This weaker understanding of the transparency of experience suffices to support premiss (iv*). If perceptual experiences are transparent in the sense that, if we attend to 
them from the inside, we notice the objects of perception and their externality, then we have introspective evidence for the claim that perceptual experiences are essentially experiences of external objects. ${ }^{\mathrm{I2}}$

There are generally good reasons to reject sense-data theory - not the least naturalist worries about the ontological status of sense-data and worries about the indeter minacy of sense-data (e.g. when what we are seeing is partly occluded by something else, so that our experience leaves us in the dark with respect to the shape or colour of the hidden part of the object perceived). But this does not mean that direct realists (whether they are intentionalists or relationalists about awareness) should not take the argument from hallucination in support of sense-data serious. In particular, that the conclusion (iv) of this argument is false does not entail that the central premiss (i) is completely unsupported. ${ }^{13}$

Sense-data theorists take the truth of (i) to be obvious, as the passages quoted above illustrate. For them, it is 'absolutely evident and indubitable' that, whenever we have a perceptual experience, there exist something that we perceive and are related to. This also explains why sense-data theorists typically do not try to support (i) by further argument. ${ }^{\mathrm{I}}$ Now, intentionalists and other opponents of sense-data theory have basically two options available to them. Either they dismiss the statements about the obviousness of (i) as completely misguided; or they accept that there is really a sense in which (i) is obvious, albeit one which does not decide the case in favour of sense-data theory.

Choosing the first option amounts to questioning the ability of sense-data theorists to distinguish what is obvious about perceptual experience from what is not. But this would be a highly uncharitable approach, since it ascribes a very fundamental er ror to sense-data theorists, namely the error of taking something to be obvious which is not. It is highly unlikely that all - or even any - of the philosophers concerned (i.e. Hume, Moore, Price, etc.) would have made such a basic error, and would have insisted on making it when being confronted with people who did not believe (i) to be true.

This leaves us with the second option of trying to find a more charitable explanation of why sense-data theorists have thought that the relationality of perceptual

${ }^{12}$ There is certainly room for controversy about which aspects of the phenomenal character of mental episodes - that is, which of their features that are accessible from the inside - are essential to the episodes concerned. But the externality of their objects is surely among the most plausible candidates: if this is not an essential aspect of the experiences, than nothing is.

${ }^{13}$ Indeed, premiss (i) need not even be false, as disjunctivists and other proponents of the combination of direct realism and relationalism would argue. The culprit might instead be premiss (iii). See, for instance, Snowdon, (1992) and Martin, (2000) for discussion.

${ }^{14}$ Even Robinson, (1994, chs. 6f.) provides only an indirect argument for what calls the 'Phenomenal Principle' (see the passage quoted earlier), namely by arguing against the two main alternative interpretations of the alleged common element in veridical perception and hallucination (i.e. the intentionalist and the adverbialist interpretation). See also the discussions in Burnyeat, (1979), Snowdon, (I992), Martin, (2000) and Brewer, (20II), to which I am heavily indebted in this section, not the least for raising the issue of how to interpret the sense-data theorists' position in the most charitable way. 
experiences is obvious. The kind of obviousness at play is certainly not the undeniability of necessary truths, given that premiss (i) does not state such a truth. Rather, we should assume that it derives from the special authority of introspective judgement. In other words, it is most charitable to assume that, at least to sense-data theorists, it is evident from the inside that perceptual experiences are relational. But if it is evident to them, it should be evident to all of us, assuming that our introspective capacities and perceptual experiences do not differ substantially from those of the sense-data theorists.

That we possess evidence from the inside for the relationality of perceptual $\mathrm{ex}^{-}$ periences, however, does not imply that many of the closely related claims of the sense-data theorists are true. First of all, access from the inside may still leave room for doubt or for potential counter-evidence. It is true that there is a strong tradition in philosophy - exemplified, for instance, by Descartes, (I64I) and Hume, (I739/2007) - to assume that introspective evidence always has the last (or the only) word on the nature of our mental episodes, or that it is inconceivable that introspection might mislead us about this nature. But there are good reasons to reject this traditional assumption of the indubitability or infallibility of our access from the inside (see, e.g., Shoemaker, (I996, especially chs. 2f. and II)). Relatedly, acknowledging that we have evidence from the inside for the relationality of perceptual experiences does not necessarily mean accepting that they are relational. Intentionalists, for example, can still insist that there are good reasons to reject premiss (i). However, in support of this rejection, they cannot just point to the intentionalist argument from hallucination, since its main premiss (iv*) about the externality of the objects of perception is sim- $^{*}$ ply grounded in the transparency of experience. Premiss (iv*) is thus backed up by evidence of the same kind and strength as premiss (i), namely evidence from the inside. And we have no reason to prefer one over the other, unless we also consider evidence from the outside.

As a result, introspection speaks equally for (or against) intentionalism and for (or against) sense-data theory. ${ }^{15}$ For the best explanation of the fact that both intentionalists and sense-data theorists point to the possibility of perfect hallucinations in support for their own view is that both notice our evidence from the inside for their main premiss (and ignore such evidence for the main premiss of their opponents). That is to say, introspection tells us (rightly or wrongly) that perceptual experiences are both relational and of external objects.

Indeed, a good case can be made for the claim that already the transparency of

I5 In fact, our evidence from the inside does indeed favour naive realism, the conjunction of the premisses (i) and (iv*). So, on the basis of evidence from the inside alone, we should perhaps rather give up premiss (iii) - as suggested, for instance, by Martin, (2004b). Note that premiss (iii) is not supported by introspection. That two experiences are indistinguishable for us from the inside does not necessarily mean that they are of the same fundemental kind. Instead, our access from the inside may not be sensitive to all differences in nature between veridical perceptions and perfect hallucinations just like our sense of vision, say, is not sensitive to differences between real fruits and perfect waxen imitations (Martin, 2004a; Martin, 2006; Williamson, I990). 
perceptual experience includes not only an impression of externality, but also an impression of relationality. That veridical perceptions are transparent means, minimally, that, if we attend to them from the inside, we notice the objects of perception and their externality. That is, we notice that our veridical experiences make us aware of external objects. ${ }^{16}$ But there are several ways in which mental episodes (as well as mental states) may make us aware of entities.

Consider first the contrast between the judgemental thought (or occurrent belief) that it rains and the occurrent desire that it rains. Both make us aware of the same proposition, but they do so in different ways. The judgemental thought regards the proposition as something that is true, while the occurrent desire regards it as something that is to be made true. This is simply part of the fact that judging (or believing) and desiring are distinct propositional attitudes. Judgemental thoughts and occurrent desires do not merely present us with propositions, they are also non-neutral about the status of those propositions - that is, about whether the propositions are true, or instead should be made true. Assuming that true propositions are, or correspond to, obtaining facts, the two attitudes are thus non-neutral about the status of those facts, too - that is, about whether the facts obtain, or instead should obtain. This difference in attitude is reflected by the fact that judgemental thoughts and occurrent desires provide answers to different questions, namely 'what is the world like?' and 'what should the world be like?' (or, alternatively, 'what do we want the world to be like?'). ${ }^{17}$

Althought veridical perceptions are not propositional attitudes, they are also nonneutral with respect to what they present us with, namely external objects and features. Seeing a green apple is more than just being aware of a green apple. We are also aware of the apple as part of our current environment, that is, as something that exists in our surroundings (an aspect which is lacking, for instance, when we simply visualise a green apple). In other words, our perceptual experience is non-neutral about the existence of the apple in our actual environment. This parallel with judgemental thought is highlighted by the fact both veridical perceptions and judgemental thoughts are meant to be answers to the same question, namely 'what is the world

\footnotetext{
${ }^{16}$ I limit the discussion here to veridical perceptions in order to be able to use the success verbs 'be aware' and 'notice' to describe the situation. But, of course, if perfect hallucinations do not differ essentially from veridical perceptions (i.e. if intentionalism is right), then they will be transparent as well, though only to intentional (i.e. not necessarily existing) objects. By contrast, relationlists about perception are likely to question whether hallucinations are transparent in the same sense as perceptions, given that they do - or should - maintain that we cannot really say much about the nature of hallucinations, at least on the basis of the evidence available to us from the inside (Dorsch, 2010a; Dorsch, 2013; Martin, 2004a; Martin, 2006). Hallucinations just (wrongly) seem to make us aware of external and existing objects.

${ }^{17}$ Velleman, (2000) describes this difference in terms of some attitudes regarding propositions as true, and others regarding them as to be made true, while Martin, (2002b) draws the contrast by reference to merely semantic representation (i.e. what is common to both judgement and desire) and stative representation (what is exclusive to judgement and the like).
} 
like?'. ${ }^{8}$

So, to return to the transparency of perceptual experience, when we attend to our veridical perceptions from the inside, we do not merely notice the external objects that they make us aware of, but we also notice these objects as part of our current environment. That is, we notice them as existing in our surroundings. This impression of existence might sometimes be misleading, namely if it also pertains to how hallucinations are given to us from the inside. But when we attend from the inside to our veridical perceptions, their objects are rightly revealed both as external and as existing. Now, noticing that the objects of perception exist may very well be understood as amounting to noticing that we stand in a genuine relation to those objects (i.e. are linked to them in a way that requires the existence of both relata). In this sense, the transparency of perceptual experience provides us also with evidence for the relationality of perception, and not only with evidence for the externality of its objects. However, the link between the impression of existence and the impression of relationality needs to be spelled out in more detail, which I intend to do in the next section.

\section{The Impression of Relationality}

According to the considerations in the preceding section, we have good reason to assume that perceptual experiences seem, from the inside, to be relations to exter nal objects and their features. But my overall aim is to motivate the claim that they seem to provide us with reasons for belief - that is, the claim that such epistemic reasons are phenomenally present to us in perception. The connective link between the impression of relationality and the impression of reason-provision consists in the specific way in which perceptual experiences are given to us as relational. It is therefore necessary to provide an analysis of what it means for perceptions to appear to be relational from the inside. In this analysis, I rely heavily on my phenomenological description of what perceptual experiences are like in Dorsch, (2OIOa).

Perhaps the most fundamental aspect of the impression of relationality is that perceptual experiences appear to be about something distinct from them. Without this impression of distinctness, experiences would not be given to us as object-directed at all (Kant, I78I/I990, B38) - as, arguably, feelings of boredom or depression are. However, from the inside, the objects of perception do not merely seem to be distinct from our experiences. They also appear to be objects of a certain ontological category,

\footnotetext{
${ }^{18}$ Note that other kinds of visual experience are non-neutral as well. Our experience of what Las Meninas depicts, for instance, is non-neutral about how many children there are (minimally) in the depicted room (i.e. there are at least four according to the picture); while our imaginative experience of a tree is likely to be non-neutral about whether it is in blossom, say, or defoliated. The difference to perceptual experience is that pictorial or imaginative experiences are not - or at least not by default - non-neutral about our actual surroundings. That is, they do not present answers to the question of how our environment is like, but rather to the question of how some imagined, depicted or otherwise fictional situation is like.
} 
and to stand in a certain relation to our perceptual experiences. I discuss these two aspects in turn.

\section{The Objects of Perception}

First of all, our perceptual experiences seem to make us aware of particular objects, that is, objects with a specific numerical identity. This means that we have the impression that there is always an answer to the question of which specific object we are perceiving - even if our perceptual experience does not by itself enable us to identify the object. When we see just one of a pair of twins, we might not be able to determine whom of the two we are facing. But our experience still gives us the impression that there is a definite answer to this question. If it did not, we would not rely on our perceptions, say, when aiming to demonstratively refer to particular objects in our environment. ${ }^{19}$ When we are visualising a man, on the other hand, we need not visualise any particular man, and the question of which specific man we are visualising may be unanswerable or even inappropriate. ${ }^{20}$

Then, perceptions seem to present us with concrete objects. That is, their objects appear to be located at a particular point in time and/or space, depending on the sense modality concerned. Just as in the case of numerical identity, the perceptual experiences may not inform us in any detail about the exact spatiotemporal location of the objects concerned (e.g. when we see something in the dark or in foggy conditions). But we none the less have the impression that there is a definite answer to the question of where the objects of perception are located. Indeed, it is natural to assume that the impression of particularity and the impression of spatiotemporal location are closely linked. The idea is that perceptual experiences seem to be about objects with specific identities partly in virtue of seeming to be about objects with determinate spatiotemporal locations, given that numerically distinct concrete objects can be individuated by their spatiotemporal location.

Finally, as already noted in section I, perceptual experiences make us aware of objects that seem to be experience-independent in their existence (and also in at least some of their perceivable features). What this means is that the objects of perception appear to be of such a kind that they can exist independently of being perceived by us. When we look at a table or a person, we have the impression that their existence does not depend on our particular experience of them. ${ }^{2 \mathrm{I}}$ This impression is missing,

\footnotetext{
${ }^{19}$ See Siegel, (2002) and Campbell, (2010). Compare also the arguments in Martin, 2002a and Soteriou, 2000 for the involvement of an impression of particularity in perceptions. Indeed, both argue that what our perceptual experiences are like from the inside is partly constituted by their specific objects. The phenomological salience of the particularity of the perceived objects has the consequence that accounts, which assume that perceptual experiences possess only a general content (e.g., Dretske, (I995) or Tye, (I995)), have serious difficulties to capture this phenomenal aspects (Martin, 2002a).

${ }^{20}$ See Dorsch, $(2017, \mathrm{ch}$. 8). Something similar is true of paintings of landscapes and other things (see Wollheim, (I998, \$ VII) and Martin, (200I, \$ IV).

${ }^{2 \mathrm{I}}$ This still leaves room for a weaker form of mind-dependence, namely that their existence depends on our general capacity to perceive them, though not on any particular manifestation of that capacity.
} 
for instance, in the case of afterimages which we take from the inside to be such that they do not exist before or after being experienced by us. This is why we do not believe that afterimages possess the same ontological status as, and are part of reality like, the tables or persons that we perceive.

\section{The Perceptual Relation}

So, from the inside, perceptions seem to relate us to particular, concrete and experience-independent objects. But what does it mean that they appear to relate us to them? There are at least two important aspects to this impression of relationality.

The first is that - as already noted at the end of section 2 - perceived objects appear to exist as part of our current environment, which means that they and their features seem to be part of the actual world (i.e. reality). If we see a book, it seems to be there, before our eyes - and not, say, merely in some imagined or fictional situation, like when we visualise a book or see a depiction of one (Dorsch, 20Iob; Martin, $2002 b$ ). More specifically, the objects of perception seem to exist in the present. This means that perceptions present their objects as existing (more or less) simultaneously with their own occurrence, and as being a certain way right at that very moment. ${ }^{22}$ Episodes of sensory recollection, by contrast, present their objects as having existed and being a certain way in the past; while episodes of sensory imagination completely lack this impression of existence. ${ }^{23}$

There is a straightforward explanation of why the impression of existence in the present is part of the impression of relationality. Genuine relations entail the concur rent existence of all of their relata. So, in order for us to stand in a perceptual relation to some object, this object has to exist. As a consequence, we are not fully aware of the relationality of our perceptual experiences, unless we are aware of the existence of the objects perceived.

McDowell, (I984/1998) argues (with respect to properties) that this weaker form of mind-dependence constitutes a kind of objectivity, partly because it leaves room for error.

${ }^{22}$ The qualification is needed to deal with the fact that the causal process leading from the object to the experience is normally extended in time. For instance, given that the speed of light is finite, our visual perceptions always occur a tiny bit after the emission of light by the perceived objects. But the temporal gaps are so small that they are usually below our threshold of discrimination. They become problematic in the visual case only with respect to objects far away from us (e.g. distant stars) which we may come to perceive some considerable time after they have gone out of existence. Besides, note that Martin describes the 'presence' of the perceived object in two different ways: in terms of spatiotemporal closeness, and in terms of constitution or counterfactual determination (cf. Martin, 20OI: 272f.). I would like to keep these two aspects apart, given that I do not want to rule out the possibility that sensory memories are also constituted or determined by their past objects, and that this fact is phenomenologically salient.

${ }^{23}$ See Sartre, (1940/2004, ch. I) and Martin, (200I). Of course, we can visualise existing objects (e.g. our friend) and be aware of the fact that we are visualising something existing. But this take on the existence of what is visualised is not part of our visual experience itself, but pertains to its wider context, such as some additional thought (what Peacocke, (I985) calls 'S-imagining') or our awareness of our own attempt at imaginative agency (Dorsch, 2012, \$3.6). 
But saying this much is compatible with the view that perception is intentional, rather than genuinely relational. For both relationalists and intentionalists about perception agree that veridical perceptions do link us to existing objects; and that hallucinatory perceptual experiences are subjectively indistinguishable from veridical ones in the sense that both seem to be, from the inside, to be veridical and to link us to some existing object. Otherwise, we could not explain why perfect hallucinations lead to belief, unless we are irrational or receive evidence from the outside that they are hallucinatory (Dorsch, 2013; Dorsch and Soldati, 2016). Relationalists and intentionalists disagree, however, about the modal status of the link between perceptions and their existing objects. While intentionalists assume this link to be merely contingent, relationalists take it to be necessary. In other words, while one and the same intentional experience could occur without the existence of its object of intentional awareness, one and the same relational experience could not occur without its object of relational awareness.

This leads us directly to the second aspect of the impression of relationality. As part of this impression, it does not merely seem to us as if the object perceived existed, but also as if our perceptual experience would not have been numerically the same if the object had not existed, and would cease to be numerically the same if the object were to go out of existence. For instance, when we see a glass on the table before us, it appears to us as if our perceptual experience would have been a different token experience if the glass had not been there on the table. This is true even if the glass would have been replaced by a distinct, but qualitatively identical glass. Although we would not have been able to notice any difference from the inside, it would still be part of our impression of the relationality of our experience that a change in the numerical identity of the object perceived would lead to a change in the numerical identity of the perceptual experience itself.

If perceptual experiences would not show this aspect, they would not be given to us from the inside as genuinely relational (i.e. as requiring the existence of their objects), but at best only as intentional (i.e. as not requiring the existence of their ob- $^{-}$ jects, or as staying neutral on this issue). Again, imaginative experiences seem to lack this aspect, given that we do not assume them to require the existence of their objects on the basis of our access to them from the inside. When we visualise a glass on some table, we do not take the identity of our experience to be bound up with the existence of the glass. Indeed, as already mentioned earlier, our imaginative experiences seem, from the inside, to be such that they could occur without there being any particular or existing glass that we are imagining. As a result, imaginative experiences involve at best an impression of intentionality, but not one of relationality.

To forestall objections, it is important to note that the view proposed here does not imply more than a minimal non-inferential access to modal status. First, the claim is not that we perceive the object as having the property of being such that their nonexistence would have led to a numerically distinct experience. Rather, the claim is that, on the basis of evidence from the inside, we take our perceptual experience to have 
the property of requiring the existence of its object. Second, access from the inside amounts to more than non-inferential conscious or introspective awareness of the mental episodes concerned. In particular, it also includes extended - and often (quasi)theoretical - reflection and reasoning on the deliverances of this non-inferential form of awareness (Dorsch, 2013). In our case here, we first notice non-inferentially that there are certain apparent differences between perceptual and imaginative experiences. But getting clearer about their specific nature (e.g. that they involve some modal differences) may require that we consider these differences in more detail by reflecting on and reasoning about them. In fact, this is what I have been doing all along in this paper. ${ }^{24}$

The impression that our perceptual experiences seem to be dependent for their existence and identity on the existence and identity of their objects may be described as an impression of determination (or constitution, if one prefers): perceptual experiences seem to be determined by their objects in so far as they would not have existed without their objects, and would have been different experiences if they had had different objects. But this impression of determinantion is not limited to the existence and the identity of the objects of perception. It also extends to their perceivable features: how perceptual experiences present their objects as being seems to us to depend on how those objects are like. When we look at a green apple, for example, we have the impression that our experience would have been different (i.e. a redrather than a green-experience) if the apple had been red, or would cease to be the same if the apple were to turn red. ${ }^{25}$ Once again, imaginative experiences differ in this respect from perceptual ones, given that they do not seem to us to depend on the perceivable features of some object. When we visualise an apple as green, we do not have the impression that the greenness of some apple is responsible for this. If at all, how our imaginative experience presents the apple as being seems to be determined by our own mental agency or by some other, more passive factor internal to our mind (e.g. memory, association, etc.). ${ }^{26}$

\section{The Impression of Reason-Provision}

In the second section, I argued that we can make sense of both the sense-data version and the intentionalist version of the argument from hallucination only if we assume that, from the inside, perceptual experiences seem to be relations to external objects.

\footnotetext{
${ }^{24} \mathrm{Or}$, in fact, some phenomenologists like Husserl, (I9OI/1984).

${ }^{25} \mathrm{~A}$ change in our point of view might also lead to a different experience, namely at least if it leads to a change in which features of the object we are perceptually aware of (e.g. the apple's red back rather than it's green front). It is an interesting question to ask whether the identity of an experience of us also nomologically depends on our specific spatial point of view - whether, for instance, two perceptual experiences, that make us aware of the same object and exactly the same features, albeit from different spatial perspectives, are distinct.

${ }^{26}$ I discuss the determination of perceptual and imaginative experiences and its phenomenological salience at length in Dorsch, (2017, chs. $5 \mathrm{ff}$.).
} 
The third section was then devoted to a more detailed description of the impression of relationality involved in perception. From the inside, perceptual experiences seem to be relational in so far as they appear to be determined by (or nomologically dependent on) their external objects. In this fourth section, I would like to defend the idea that this impression of determination amounts to an impression of the presence of a perceptual reason for belief - at least in the case of veridical perceptual experiences. ${ }^{27}$

In the following, I assume that such experiences do provide us with reasons for belief. ${ }^{28}$ That is, unless we are aware of any defeaters, seeing a green apple is sufficient to justify - and move - us to believe that there is an apple and that the apple is green. But I aim to stay neutral on the question of what perceptual reasons are. Perhaps they are the facts (or, if one prefers, the property instances) that our veridical perceptual experiences make us aware of. But maybe they are rather the experiences themselves. ${ }^{29}$ In both cases, it makes sense to speak of the veridical perceptual experiences as providing us with reasons: either they give us access to them, or they constitute them.

But in virtue of which feature(s) do veridical perceptual experiences provide us with reasons for belief? When trying to answer this question, the first thing to note is that these experiences make us aware of external objects in our environment and some of their features. That is, they present certain parts of our actual surroundings as being a certain way. For instance, we may see the apple on the table before us, and we may see it as being green and fresh. Moreover, which objects veridical perceptual experiences present us with, and how they present them as being, is determined by (or nomologically depends on) the relevant parts of our surroundings. That there is

\footnotetext{
${ }^{27}$ I ignore perfectly illusory and hallucinatory experiences for two reasons. First, to make the case for the phenomenal presence of perceptual reasons, it suffices to concentrate on veridical perceptions. Second, there is just not the space here to properly address the issue of illusions or hallucinations since this would require to engage in much more detail with the various views on their nature and, notably, on whether they possess any justificatory force (see Dorsch, (2013) and Dorsch, (2OIOb) for discussion). However, if illusions or hallucinations do provide us with reasons for belief, they do so not because they are determined by reality (since they are not, or not fully), but because they are experiences of the very same kind as perceptual experiences and thus would have been nomologically dependent on reality, had they occurred under more normal or more suitable conditions (i.e. conditions under which they would not have counted as illusory or hallucinatory). Besides, there is the further issue of whether we have any access from the inside to the nature of non-veridical experiences. For that they are subjectively indistinguishable from veridical perceptions does not entail that they are experiences of the same kind (Martin, 2004a; Martin, 2006). Hence, although we form the same introspective beliefs about veridical and (perfect) non-veridical experiences, they need not constitute knowledge in both cases. For instance, our specific introspective belief that one of our experiences possesses justificatory power (e.g. based on an impression of reason-provision) may constitute knowledge if it is about a veridical perception, but perhaps not if it is about a hallucination.

${ }^{28}$ See Martin, (I992) for a good argument in support of this claim.

29 There is in fact a third candidate for perceptual reasons which, in some sense, combines the other two: namely the fact that we are seeing some fact or property instance (Haddock, 20IO; McDowell, I998). But I take it that this option is equally compatible with what I am going to say than the two alternatives mentioned in the main text.
} 
a bent banana before us (and that we are facing it with open eyes, in broad daylight, and so on) is responsible for the fact that we see a banana, and also that we see it as being bent. ${ }^{30}$ If the banana had been straight, we would have seen it as being straight. If there had been a pear instead of the banana, we would have seen a pear, and not the banana. And if there had been nothing on the table, we would not have seen anything (over and above seeing the table). ${ }^{3 \mathrm{I}}$

We can now see why veridical perceptual experiences provide us with reasons for belief about the external world: namely precisely in virtue of the special way in which they are connected to, and make us aware of, this world. How veridical perceptual experiences present aspects of reality as being is nomologically dependent on how those aspects are really like. Because of this, the experiences (or what they make us aware of) speak for the truth of the corresponding propositions about reality. Seeing a bent banana speaks in favour of - and thus provides us with a reason for - believing that there is a banana which is bent. And it does so because we see the banana and see it as bent due to the fact that there is a bent banana. Indeed, we could hardly receive better evidential support for the belief that there is a banana with a certain shape than by enjoying an experience of the banana that is determined by the actual shape of the banana. In particular, experiences (or other kinds of mental episode) could not be responsive in an epistemically more direct way than this to how our current environment is qualitatively like..$^{32}$

Of course, there are other ways in which mental episodes or states may provide us with reasons for belief. That is, there are other ways in which episodes or states (or what they are about) may speak for the truth of some proposition. For instance, our knowledge-constituting belief that $p$ and $p \rightarrow q$ provides us with a reason to be-

${ }^{30}$ The same is true of colours, even if they turn out to be secondary qualities: which colour we see the apple as having is determined by which colour it actually possesses. But if colours are secondary qualities, which colour an object possesses depends again both on its reflectance properties and on how the human visual system works (Dorsch, 2009a). Assuming that our visual system does not change (or that colours are defined in a rigid way by reference to our current visual system), it follows that which colour we see the apple as having is (primarily) determined by which reflectance properties its surface has. The only adjustment to be made is perhaps that the determinant features of objects need not always be perceivable (given that we perhaps do not see reflectance properties, but only colours). However, even shapes are ultimately determined or constituted by non-perceivable physical properties, so that shape perception shows the same dependence on the non-perceivable.

${ }^{31}$ It is worthwhile to point out that these considerations are in fact true irrespective of whether perception is relational or intentional. For even intentionalists agree that veridical perception makes us aware of existing objects, the perceivable nature of which determines how we perceive them as being (Dorsch and Soldati, 2016; Dretske, 1995; Tye, 1995). Indeed, intentionalists may be able to accept that the numerical identity of the objects perceived (if there are any) may also play a determining role with respect to perceptual experience, even though such experience does not require the existence of its objects (Martin, 2002a).

${ }^{32}$ In order to be sensitive to differences in numerical identity (e.g. when grounding demonstrative knowledge), something more might be needed, namely genuine relationality (see Siegel, (2002), Campbell, (2OIO) and Martin, (20O2a) for discussion). In this chapter, I focus solely on descriptive perceptual knowledge about external objects. 
lieve $q$ in so far as our belief (or the truth) of $p$ and $p \rightarrow q$ speaks for the truth of $q$. This suggests that we can understand the property of providing us with a reason for belief as a determinable property that may be determined in different ways. While knowledge-constituting beliefs, say, may possess this determinable property in virtue of being formed in response to sufficient evidence for their own propositional content, veridical perceptual experiences possess it in virtue of being determined by reality.

But, as I argued earlier, veridical perceptual experiences also involve the impression of relationality - that is, of being determined by the nature of their existing and external objects. What this means is that we have access from the inside to the feature in virtue of which the experiences provide us with reasons for belief. Veridical perceptual experiences are reason-providing because of their nomological dependence on reality; and they seem to us to be nomologically dependent on reality as part of their apparent relationality. It is in this sense that perceptual reasons are phenomenally present to us: from the inside, veridical perceptual experiences seem to possess a property (i.e. the property of being determined by reality) which is a determinant of the determinable property of being reason-providing.

This impression is phenomenal because it already occurs on the level of non-inferential - and non-conceptual - access from the inside. For instance, we can notice the difference in determination between perceptual and imaginative experiences without having to engage in any form of reflection or reasoning. The latter are only needed if we want to describe this difference in any detail. The situation is thus analagous to our visual awareness of hues, say. We can discriminate different shades of red without using our capacities for reflection and reasoning. This parallel is also pertinent with respect to the shared independence from concepts. We need not be able to conceptualise the difference between two shades of colour (other than perhaps the concepts 'this colour' and 'that colour') in order to visually distinguish and individuate them. Similarly, we do not have to possess the concepts 'determination' or 'reason-provision' (though perhaps the concepts 'this episode' and 'that episode') in order to notice from the inside the difference in question between perceptual and imaginative experiences.

Because of this independence of the conceptual and reflective capacities required for normative judgement or belief, there is no principle barrier for infants to be capable of discriminating perceptual (and possibly other) reasons phenomenally - just as they are capable of visually discriminating hues. Hence, experiential rationalism and, with it, experientialism more generally - can hold on to the claims (I), (2) and (3), given that they are jointly inconsistency only on the assumption of doxasticism.

The categorisation of our impression of reason-provision as phenomenal also fits with standard terminology. It is natural to assume that those aspects or properties of mental episodes that are are accessible from the inside constitute their phenomenal character (i.e. what the episodes are like for us). ${ }^{33}$ Hence, the property of providing us with reasons forms part of the phenomenal character of veridical perceptual experi-

\footnotetext{
${ }^{33}$ See, for instance, (Martin, 2004b; Williamson, 1990), and also footnote 9.
} 
ences. And our awareness from the inside of this property is an instance of phenomenal awareness, given that it makes us aware of an aspect of phenomenal character.

Given that there are different conceptions of reasons, there are also different ways of further spelling out the description of the impression of reason-provision. If perceptual reasons are identical with the facts perceived, they are phenomenally present in so far as veridical perceptual experiences seem to be determined by the reason-constituting facts). While both perceptual and imaginative experiences make us aware of states of affairs (i.e. objects and their features), only the first kind of experience phenomenally marks these states of affairs as obtaining and as constituting reasons. The impression of reason-provision is then an impression of the provision of access to reason-constituting facts. Alternatively, if perceptual reasons are identical with the perceptual experiences themselves, they are phenomenally present in so far as the reason-constituting experiences seem to be determined by external facts. ${ }^{34}$ In this case, the experiences phenomenally mark themselves as reasons, and the impression of reason-provision is an impression of reason-constitution.

But whichever way of understanding reasons is to be preferred, both options have in common that the central aspect of the impression of reason-provision is the impression of determination by aspects of our actual environment, which is again part of the impression of relationality. Moreover, the two alternatives share the view that the impression is just one of the presence of some perceptual reason for belief. ${ }^{35}$ In other words, the impression is neutral on which specific reason for belief is concerned. In particular, it does not say anything about which specific belief it is a reason for. For that a given veridical perceptual experience provides us with a reason for believing $p$ (rather than $q$ ) is not a matter of the relationality of the experience, but rather of its content, that is, how it presents things as being. If the experience makes us aware of a green apple, say, it provides us with a reason for believing that there is a green apple; while if we experience a yellow banana, we have a reason to judge that there is a yellow banana. The impression of the presence of a specific perceptual reason is thus the result of the combination of the general impression of relationality and determination and the particular impression of having a specific content.

\section{Non-Sensory Aspects of Phenomenal Character}

With the preceding section, I have finished making my case for experientialism about our access to reasons and, in particular, for the idea that perceptual reasons are phenomenally present in perceptual experience. This is a first, good indication for the

\footnotetext{
${ }^{34}$ It is an interesting question to ask, if reason-constituting facts determine perceptions, whether they do so in a rational way, or merely by means of causation or constitution.

35 Indeed, the reason may be salient as a perceptual reason, meaning that it may seem to be, from the inside, to be a special kind of epistemic reason, namely an epistemic reason that is conclusive (i.e. on its own sufficient to ground belief and knowledge), but also merely prima facie (i.e. defeasible by relevant counterevidence).
} 
truth of experiential rationalism, at least with respect to perceptual and other sensory experiences. In the remainder of the chapter, I would like to highlight one particular aspect of the philosophical significance of the impression of reason-provision. For its existence suggests that the recently prominent debate about whether our access from the inside is limited to sensory aspects of experiences should not focus - or at least not entirely - on intellectual aspects (i.e. what is sometimes called 'cognitive phenomenology'), but rather on structural aspects.

It has indeed been a central question in the recent philosophy of mind to ask whether there are any non-sensory aspects of mental episodes that make a difference from the inside. Sensory aspects of mental episodes are features that pertain to the sensory (or experiential) presentation of objects and their features. For instance, two visual experiences that differ in which colour or shape they make us aware of differ in sensory presentation. There is wide agreement that such sensory aspects contribute to how the mental episodes concerned appear to be like from the inside. But it is a controversial issue whether our access from the inside is limited to sensory aspects. ${ }^{36}$

Typically, the debate about this issue focuses on the question of whether we enjoy access from the inside to our thoughts. The main reason for this is that - at least to a common view - experiences and thoughts make us aware of objects and their features in very different ways. More specifically, the kind of presentation involved in thought is not sensory, but intellectual (or cognitive). This raises the issue of whether differences in thought content - that is, differences in the concepts or propositions involved - are accessible from the inside, too. Experiences of red objects and experiences of green objects seem to us to differ because they present their objects as having different colours. So, the question is whether the same is true of thoughts about red objects and thoughts about green objects - that is, whether we can notice from the inside whether a given thought includes the employment of the concept 'red' rather than that of the concept 'green'. If the answer to this question turns out to be positive, we have a good example of non-sensory aspects of mental episodes that are accessible from the inside - namely intellectual aspects pertaining to thoughts.

However, the respective debate does not properly distinguish between three different issues: (i) whether non-sensory aspects are accessible from the inside; (ii) whether any aspects of thoughts are accessible from the inside; (iii) whether intellectual aspects (of thoughts) are accessible from the inside. In particular, what is ignored is the possibility that our access from the inside may extend to aspects of experiences or thoughts that pertain neither to the sensory, nor to the intellectual presentation of objects and their features. As a result, (i) is often wrongly reduced to (ii) or (iii). One problem with this reduction is that the focus of the debate stays exclusively on

\footnotetext{
${ }^{36}$ See, for instance, Carruthers and Veillet, (201I) or, more generally, the papers in (Bayne and Montague, 20II). Some philosophers deny altogether that we enjoy any access from the inside to our mental episodes (Churchland, 1984; Dennett, I99I). Of course, if this radical scepticism should turn out to be true, the whole approach adopted in this paper would be undermined. But there are good reasons to reject the idea that our only - or even our primary - access to our experiences (and possibly also our thoughts) is from the outside (Soldati, 2007).
} 
thoughts (or other propositional attitudes) and, especially, on their accessibility from the inside. ${ }^{37}$ Fortunately, we can circumvent the whole issue of whether introspection extends to thoughts by asking instead whether already perceptual experiences involve non-sensory aspects that are accessible from the inside. In this way, we can avoid any sceptical considerations about thoughts and start with the wide acknowledgement that we do enjoy introspective access to experiences - the question is only to which of their aspects.

In the light of the preceding observations about perceptual experiences, the answer should clearly be that there is indeed another class of non-sensory aspects that are accessible from the inside. For the impressions of relationality and reason-provision are neither sensory, nor intellectual. Instead, they belong to the class of what may be called structural aspects. Structural aspects of mental episodes are characterised by the fact that they do not vary between particular instances of a given kind of episode. The relationality and reason-providing character are structural features because they pertain to all perceptual experiences, and not only some. By contrast, distinct experiences or thoughts usually differ in their sensory or intellectual aspects, simply because they usually differ in what they make us aware of.

It is true that, as part of the impression of reason-provision, the objects of perception appear to us to possess certain properties: they seem to be distinct from the perceptual experiences concerned, to be concrete, to exist independently of being experienced, and to determine how they are experienced by us. But they do not appear to have these properties in the same sensory way in which they seem to be red or round, say. That is to say, we do not sensorily perceive properties like existence or externality.

Indeed, if these properties were sensorily perceivable, there should be a specific 'look' that all existing and external objects share, but other objects lack, and which would allow us to visually discriminate the first from the second. However, there is no such 'look', mainly for two reasons. First, we cannot perceptually experience an object without it seeming to exist and be external. Hence, we cannot, just on the basis of this impression, distinguish different kinds of object. Second, properties like existence or externality are - unlike perceivable Gestalt or other higher-level properties not systematically linked to certain sets of lower-level perceivable properties (such as shapes, colours, textures, and so on). We can visually discriminate apples from other fruits because they possess a characteristic size, shape, texture and range of colours. By contrast, existing and external objects come in all kinds of sizes, shapes, textures, colours, and so on.

Besides, it might be tempting to characterise all structural aspects as pertaining to the attitude of the experiences and thoughts, while insisting that the sensory and intellectual aspects pertain to their content. But this would be incorrect, given that experiences cannot be construed as attitudes towards contents (at least not in the same

\footnotetext{
${ }^{37}$ See, for instance, Carruthers and Veillet, (20II) and, more generally, the papers in Bayne and Montague, (20II).
} 
way as propositional attitudes). This is reflected by the fact that we can stay neutral towards a proposition (i.e. entertain it without judging or supposing it to be true), but not towards the experiential presentation of objects and their features. Consider the moment in which you recognise that you have been the victim of a trompe-l'œil. What happens then is that the objects, which a second ago seemed to exist as part of our current environment, now appear to pertain to some depicted scene. But this change is not due to the adoption of a different attitude towards how the objects are presented. Rather, what gets modified is how the objects are (non-sensorily) presented - namely, as present in, or absent from, our surroundings. ${ }^{38}$

To conclude, what we have access to from the inside goes beyond the sensory (e.g. visual) presentation of objects and their features. In particular, experiential rationalism is right in claiming that the rational role of perceptual experiences - that is, their justificatory power - is salient to us in introspection. That is, it makes a difference for us whether we are enjoying an experience that provides us with a reason for belief, or an experience that does not. As a consequence, sceptics about intellectual or cognitive aspects - and, more generally, non-sensory aspects - of the phenomenal character of mental episodes should worry not only about the intellectual aspects of thoughts, but also about the structural aspects of experiences. ${ }^{39}$

Indeed, the primary focus of the debate on non-sensory aspects of phenomenal character should be on the structural aspects, mainly for two reasons. First, structural aspects belong to all kinds of mental episode - including sensory experiences that are widely accepted to be accessible from the inside - and are therefore more difficult to deny than intellectual aspects, which perhaps pertain only to thoughts and other occurrent propositional attitudes. Second, the structural aspects are more significicant and fundamental than the sensory and the intellectual aspects. For the structural aspects reflect the general nature of the natural kinds of mental episode concerned, rather than the specific and contingent presentational differences among their instances. In particular, the structural aspects render the rational role of the mental episodes - whether they provide us with reasons or are themselves sensitive to reasons - accessible from the inside (Dorsch, 20II, Introduction). The debate should therefore shift at least part of its attention to the structural aspects of mental episodes.

${ }^{38}$ This, I think, is part of what is behind Hume's suggestion that there is a fundamental divide between perceptual experiences (i.e. 'impressions'), on the one hand, and mnemonic and imaginative experiences (i.e. 'ideas of the memory and the imagination'), on the other. See also Sartre, (1940/2004, ch. I), Martin, (20OI), Martin, (2002b) and Dorsch, (2OIOb) for discussion.

39 And indeed thoughts, given that judgemental thoughts or occurrent beliefs also provide us with reasons for belief, albeit in virtue of seeming to be themselves based on sufficient reasons (Dorsch, $2009 \mathrm{~b}, \$ 4)$. 


\section{Bibliography}

Bayne, Tim and Michelle Montague, eds. (20II). Cognitive Phenomenology. Oxford: Oxford University Press.

Bealer, George (2002). "Modal Epistemology and the Rationalist Renaissance". In: Conceivability and Possibility. Ed. by Tamar Gendler and John Hawthorne. Oxford: Oxford University Press.

Brewer, Bill (20II). Perception and Its Objects. Oxford: Oxford University Press.

Burnyeat, Myles (I979). "Conflicting Appearances". In: Proceedings of the British Academy 65, pp. 69-III.

Campbell, John (2010). "Demonstrative Reference, the Relational View of Experience, and the Proximality Principle". In: New Essays on Singular Thought. Ed. by Robin Jeshion. Oxford: Oxford University Press, pp. 193-213.

Carruthers, Peter and Benedicte Veillet (20II). "The Case Against Cognitive Phenomenology". In: Cognitive Phenomenology. Ed. by Timothy Bayne and Michelle Montague. Oxford: Oxford University Press, pp. 35-56.

Churchland, Paul (1984). Matter and Consciousness. The MIT Press.

Dancy, Jonathan (2000). Practical Reality. Oxford: Oxford University Press.

Davidson, Donald (I982). "Rational Animals". In: dialectica 36.4, pp. 317-327.

Dennett, Daniel (I991). Consciousness Explained. New York: Little, Brown and Company.

Descartes, Rene (I64I). Meditations on First Philosophy.

Dorsch, Fabian (2009a). Die Natur der Farben. Berlin: De Gruyter, p. 493.

- (2009b). "Judging and the Scope of Mental Agency". In: Mental Actions. Ed. by Lucy O'Brien and Matthew Soteriou. Oxford: Oxford University Press, pp. 38-7I.

- (2OIOa). "The Unity of Hallucinations". In: Phenomenology and the Cognitive Sciences 9.2, pp. I7I-I9I.

- (2010b). "Transparency and Imagining Seeing”. In: Philosophical Explorations 13.3, pp. $173^{-200 .}$

- (20II). Experience and Reason. Lausanne: Rero Doc, p. 408.

- (2012). The Unity of Imagining. Berlin: De Gruyter, p. 485.

- (2013). "Experience and Introspection". In: Hallucination. Ed. by Fiona Macpherson and Dimitris Platchias. Cambridge (Mass.): MIT Press, pp. 175-220.

- (2017). Imagination. London: Routledge.

Dorsch, Fabian and Gianfranco Soldati (2016). "Naive Realism and Errors in Experience". Manuscript.

Dretske, Fred (1995). Naturalizing the Mind. Cambridge (Mass.): MIT Press.

Haddock, Adrian (2010). "Knowledge and Action”. In: The Nature and Value of Knowledge: Three Investigations. Ed. by Duncan Pritchard, Alan Millar, and Adrian Haddock. Oxford: Oxford University Press. 
Hume, David (1739/2007). A Treatise of Human Nature: a Critical Edition. Ed. by David Fate Norton and Mary J Norton. The Clarendon edition of the works of David Hume. Oxford: Clarendon Press.

Husserl, Edmund (1901/1984). Logische Untersuchungen. Vol. 2. Den Haag: Nijhoff.

Kant, Immanuel (I78I/I990). Kritik der Reinen Vernunft. Meiner.

- (I785/1999). Grundlegung zur Metaphysik der Sitten. Hamburg: Meiner.

Martin, M. G. F. (I992). "The Rational Role of Experience". In: Proceedings of the Aristotelian Society 93, pp. $7 \mathrm{I}^{-}-88$.

- (2000). "Beyond Dispute: Sense-Data, Intentionality, and the Mind-Body Problem". In: History of the Mind-Body Problem. Ed. by Tim Crane and Sarah Patterson. Routledge, pp. 195-23I.

- (200I). "Out of the Past: Episodic Recall as Retained Acquaintance". In: Time and Memory. Ed. by Christoph Hoerl and Teresa McCormack. Oxford: Oxford University Press, pp. 257-284.

- (2002a). "Particular Thoughts and Singular Thought". In: Royal Institute of Philosophy Supplement 5I, pp. 173-2I4.

- (2002b). "The Transparency of Experience". In: Mind and Language I7.4, pp. 376425 .

- (2004a). "The limits of self-awareness". In: Philosophical Studies I20, pp. 37-89.

- (2004b). "Uncovering Appearances". Manuscript. Oxford.

- (2006). "On Being Alienated". In: Perceptual Experience. Ed. by Tamar Gendler and John Hawthorne. Oxford: Oxford University Press, pp. 354-4IO.

McDowell, John (I984/1998). "Values and Secondary Qualities". In: Mind, Value, and Reality. Cambridge (Mass.): Harvard University Press, pp. IIO-I29.

- (I998). Mind and World. Cambridge (Mass.): Harvard University Press.

Mele, Alfred R. (2003). Motivation and Agency. Oxford: Oxford University Press.

Moore, George E. (1903). "The Refutation of Idealism”. In: Mind I2, pp. 433-53.

Nudds, Matthew (2009). "Recent Work in Perception: Naive Realism and its Opponents". In: Analysis 69.2, pp. 334-346.

Peacocke, Christopher (I985). "Imagination, Experience and Possibility". In: Essays on Berkeley. Ed. by Howard Robinson and John Foster. Oxford: Clarendon Press.

- (2009). "Mental action and self-awareness (II): Epistemology". In: Mental Actions. Ed. by Lucy O'Brien and Matthew Soteriou. Oxford: Oxford University Press, USA, p. 192.

Price, H. H. (I98I). Perception. Westport, Conn.: Greenwood Press.

Robinson, Howard (1994). Perception. London: Routledge.

Sartre, Jean P (1940/2004). The Imaginary: A Phenomenological Psychology of the Imagination. London: Routledge.

Sellars, Wilfrid (1956/1997). Empiricism and the Philosophy of Mind.

Setiya, Kieran (2OII). "Reasons and Causes". en. In: European fournal of Philosophy I9.I, pp. $129-157$. 
Shoemaker, Sydney (1996). The First-Person Perspective and other Essays. Cambridge: Cambridge University Press.

Siegel, Susanna (2002). "The Role of Perception in Demonstrative Reference". In: Philosophers' Imprint 2.I, pp. I-2I.

Smith, Michael (1994). The Moral Problem. Oxford: Blackwell.

Snowdon, Paul (1992). "How to Interpret 'Direct Perception'”. In: The Contents of Experience. Ed. by Tim Crane. Cambridge: Cambridge University Press.

Soldati, Gianfranco (2007). "Subjectivity in Heterophenomenology". In: Phenomenology and the Cognitive Sciences 6.I, pp. 89-98.

Soteriou, Matthew (2000). "The Particularlity of Visual Perception". In: European Fournal of Philosophy 8.2, pp. I73-189.

Tye, Michael (1995). Ten Problems of Consciousness. Cambridge (Mass.): MIT Press.

Velleman, David (200o). "On the Aim of Belief". In: The Possibility of Practical Reason. Oxford: Oxford University Press.

Williamson, Timothy (I990). Identity and Discrimination. Oxford: Blackwell.

Wollheim, Richard (1998). "On Pictorial Representation”. In: The fournal of Aesthetics and Art Criticism 56.3, pp. 217-226. 